\title{
LA LIBERTAD DE EXPRESIÓN Y LA DEFENSA DE LOS DERECHOS HUMANOS EN MÉXICO: SITUACIÓN ACTUAL

\author{
FREEDOM OF EXPRESSION AND THE DEFENSE OF HUMAN RIGHTS IN MEXICO: \\ CURRENT SITUATION
}

\section{Selene Villanueva Sossa* y José de Jesús Chávez Cervantes**}

RESUMEN: La libertad de expresión es un derecho aún pendiente por garantizar por parte del Estado mexicano si éste se considera comprometido con el resguardo de los derechos humanos. Prueba de lo anterior, son las numerosas violaciones de sus derechos a periodistas y personas defensoras de derechos humanos, lo que se traduce en un Estado en el que ejercer la libertad de expresión, se puede estar firmando una sentencia de muerte.

ABSTRACT: Freedom of expression is a still pending right to be guaranteed by the Mexican State if he considers itself committed with the safeguarding human rights. Proof of the previous text, are the numerous violations to journalist rights and human right defenders, which it translates into a state in which to exercise freedom of expression, could be a death sentence.

PALABRAS CLAVE: libertad de expresión, derechos humanos, estado constitucional, México

KEYWORDS: freedom of expression, human rights, constitutional state, Mexico

Fecha de recepción: 16/04/2018

Fecha de aceptación: 08/06/2018

doi: https://doi.org/10.20318/universitas.2018.4309

* Candidata a Doctora en Estudios Avanzados en Derechos Humanos. Instituto de Derechos Humanos Bartolomé de las Casas. Universidad Carlos III de Madrid, España. E-mail: selenevillanueva29@gmail.com

** Candidato a Doctor en Estudios Avanzados en Derechos Humanos. Instituto de Derechos Humanos Bartolomé de las Casas. Universidad Carlos III de Madrid, España. E-mail: chavezcervantes26@gmail.com 


\section{1.- INTRODUCCIÓN}

El año 2018, representa una anualidad de suma importancia para el Estado mexicano, ya que el país se engalana en la organización de elecciones electorales en las que saldrá un vencedor que al poco tiempo después del mes de Julio, habrá que llamarle Presidente de los Estados Unidos Mexicanos. Asimismo, se renovará el Congreso de la Unión o Parlamento, es decir, los 500 integrantes de la Cámara de Diputados y los 128 miembros de la Cámara de Senadores, serán sustituidos mediante elección electoral donde el pueblo es el protagonista, ya sea de forma directa o indirecta. Lo anterior, es especialmente relevante para nuestro tema de estudio, pues al hilo de la escritura del presente artículo es común escuchar casi de forma unánime a los candidatos y candidatas de los distintos puestos de elección popular, su leal y sagaz compromiso con la defensa y protección de los derechos fundamentales. Incluido, evidentemente, el de la libertad de expresión. Pareciera, que todos los partidos políticos tienen un sentir común, a saber: el respeto y defensa de los derechos fundamentales.

Sin embargo, la bandera de los derechos se ve por demás difuminada una vez finalizadas las campañas políticas; es como si la bandera de los derechos, se alzará únicamente en tiempos electorales. Así, vemos con total desagrado, que uno de los derechos que pide a gritos su defensa es, efectivamente, el derecho a la libertad de expresión. México, es un país que por desgracia la libertad de expresión encuentra límites, pero no solamente aquellos que la propia doctrina deriva, pues es de saber que los derechos tienen límites ${ }^{1}$; sin embargo, nos referimos a límites que no tienen nada que ver con el Derecho, es decir, la práctica de la libertad de expresión ha supuesto un riesgo para quienes hacen de su vida cotidiana la manifestación de sus ideas, inclusive también para los defensores y defensoras de derechos humanos.

Lo anterior, es el telón de fondo del presente estudio que, en pocas palabras podemos sintetizar con la siguiente afirmación: el ejercicio de la libertad de expresión es un derecho que sugiere una grave amenaza, tanto para quienes buscan difundir sus ideas así como para aquellas personas que defienden y promueven los derechos humanos en México. Para dar cuenta de lo anterior, abordaremos brevemente los siguientes apartados:

1 AGUIAR DE LUQUE, L., "Los límites de los derechos fundamentales", Revista del Centro de Estudios Constitucionales, $\mathrm{n}^{\circ}$ 15, 1993, pp. 9-34. Revisar también las paradojas que resultan en torno a los derechos como límites al poder. Al respecto véase: DE ASÍS ROIG, R., Las paradojas de los derechos fundamentales como límites al poder, Ed. Dykinson, Instituto de Derechos Humanos Bartolomé de las Casas, Universidad Carlos III de Madrid, 2000. 
En primer lugar, veremos la importancia del derecho a la libertad de expresión en un Estado que suele denominarse como democrático, esto es, sin la garantía de tan importante derecho, no es posible hablar de Estado democrático. En otro apartado, nos dedicaremos a señalar las principales herramientas jurídicas que tiene el Estado mexicano con el objeto de garantizar la libertad de expresión, tanto a nivel local como aquellos instrumentos que tienen su origen en el llamando derecho internacional de los derechos humanos. Una vez abordados los epígrafes mencionados, daremos cuenta de la situación actual en México, apoyados por un Informe que ha sido publicado tanto por el Relator especial de la ONU sobre libertad de expresión, así como el Relator especial sobre la libertad de expresión de la Corte Interamericana de Derechos Humanos. Dicho documento ha sido publicado apenas el pasado 2017, en donde constataremos el reclamo internacional hacía el Estado mexicano por la violación sistemática a tan vital derecho; exhortando entonces que se busquen soluciones inmediatas para garantizarlo. Finalmente, llevaremos a cabo una serie de reflexiones en el sentido de lo que falta por hacer, demandando que la libertad de expresión sea de una vez por todas tomada en serio, pues de ser así, será tomarse en serio la democracia y por consiguiente la Constitución.

Antes, consideramos oportuno mencionar algunas puntualizaciones. El derecho de expresar el propio pensamiento, repercute además el de buscar, recibir y difundir información e ideas de toda índole. Es decir, el derecho a la libertad de expresión es, en efecto, un medio que protege el intercambio de ideas e informaciones, resguardando entonces tanto la comunicación a otras personas como los propios puntos de vista, así como el derecho de tener la información de otras opiniones. Por tanto, ambas dimensiones deben estar correctamente garantizadas simultáneamente para que tenga plena efectividad el ejercicio a la libertad de expresión y pensamiento. No está por demás mencionar que tanto la expresión y la difusión del pensamiento son derechos que son indivisibles, de modo que la restricción de divulgación de información, repercute el derecho a expresarse libremente, esto es, en la medida que se violente alguna dimensión, será entonces el límite para su pleno ejercicio ${ }^{2}$. En definitiva, la libertad de expresión y su vertiente consisten en el derecho a la información y su doble dimensión, tanto individual como social, en donde se exige que no únicamente las personas vean trasgredida la posibilidad de poder manifestar sus ideas libremente y con temor a sufrir algún tipo de represalia, (como el caso mexicano) sino que se

${ }^{2}$ La Corte Interamericana de Derechos Humanos, ha hecho hincapié en lo anterior. Véase: la Opinión Consultiva OC-5/85 del 13 de noviembre de 1985 y el caso Olmedo Bustos y otros vs. Chile (caso "La última tentación de Cristo") resuelto en sentencia de 5 de febrero de 2001. 
Villanueva Sossa y Chávez Cervantes - La libertad de expresión y la defensa de los derechos humanos...

debe de resguardar el derecho que como miembros de una determinada comunidad política, de recibir información y conocer por tanto la expresión de otras personas, o sea, la expresión del pensamiento ajeno.

\section{2.- LA LIBERTAD DE EXPRESIÓN EN EL ESTADO CONSTITUCIONAL}

Previamente de examinar la relación que existe entre la libertad de expresión y el Estado Constitucional, veremos brevemente algunas dimensiones de lo qué es la libertad, así como, posteriormente, lo que se entiende por Estado Constitucional. Lo anterior, nos permitirá enlazarnos a nuestro tema capital, pero sobre todo, nos ayudará a justificar que la libertad de expresión es un pilar del Estado Constitucional y por lo tanto de la democracia. En tanto, se quiera ser denominado como Estado democrático.

Pues bien, desde un inicio, es importante mencionar que la libertad es la clave de bóveda de la fundamentación de los derechos ${ }^{3}$. Lo anterior es posible, gracias a la conexión que existe entre una cierta moral y la libertad. En otras palabras, "la libertad es una condición imprescindible para la acción, que permite alcanzar a cada individuo los objetivos y fines morales que persiga y que son la expresión de la dignidad humana, que su consideración como fin en sí, como algo valioso"4. En efecto, la libertad es el eje central que toda persona necesita para lograr sus fines y alcanzar las metas propuestas. Sin embargo, el concepto de libertad así descrito, es general y muy seguramente problemático. Prueba de lo anterior, se constata por los distintos enfoques que permite su estudio; incluso, se ha utilizado para fungir como la antítesis entre el liberalismo y la democracia, aludiendo entonces a la libertad de los antiguos como contraposición de la libertad de los modernos. Dicha distinción, fue sutilmente argumentada y anunciada por el francés Benjamin Constant en un célebre discurso dictado en 1818 en el que expone la difícil tarea que demanda por un lado limitar al poder y por otro, la distribución del poder. Así, la libertad de los antiguos tiene tintes democráticos, pues en tiempos pasados, los ciudadanos se preocupaban por pactar una mayor participación en el ejercicio del poder político. Caso contrario para la libertad de los modernos, ya que para este tipo de libertad lo que pretende es garantizar una esfera de independencia de los ciudadanos frente al poder. Por tanto, es identificable con un modelo liberal, pues en este, según Constant, para los modernos la prioridad es la tranquilidad. De

\footnotetext{
3 PECES-BARBA MARTÍNEZ, G., Curso de derechos fundamentales. Teoría General, Ed. Universidad Carlos III de Madrid, Boletín Oficial del Estado, Madrid, 1995, p. 215.

4 PECES-BARBA MARTÍNEZ, G., Lecciones de derechos fundamentales, Ed. Dykinson, Madrid, 2004, p. 135.
} 
ahí, que para lograr dicho estado de paz será necesario una pequeña cantidad de leyes que impidan que las personas sean molestadas, respetando así, la libertad individual ${ }^{5}$.

Independientemente de la arbitraria transposición histórica que ha llevado Constant entre la libertad de los antiguos y modernos, (según Bobbio) es de gran mérito la diferenciación que ha captado el autor con respecto a los tipos de libertad. A pesar de su inclinación por un modelo liberal, Constant ha sido precursor del estudio del principio de la libertad, intensificando el debate y tensión en relación a un modelo ideal de libertad 6 .

Ahora bien, consideramos de gran ayuda la propuesta de PecesBarba para esclarecer las distintas dimensiones que tiene el concepto de libertad, a saber: como no interferencia o protectora; promocional y; participación. Veamos brevemente cada una de ellas. La libertad como no interferencia o protectora, demanda que el ser humano puede actuar y decidir libremente. Generalmente, este tipo de libertad fundamenta los derechos individuales y civiles, por ejemplo: el derecho a la vida, pensamiento, conciencia, expresión, reunión, garantías procesales, manifestación, de comunicaciones; por otro lado, la libertad denominada promocional, pretende satisfacer una serie de necesidades que impidan o en su defecto, que dificulten el ejercicio de la libertad como no interferencia. En este caso, el tipo de derechos que fundamenta la libertad promocional, se da según el tipo de necesidades, que pueden ser: radicales, de mantenimiento o mejora. Las denominadas radicales, son aquellas que pretenden otorgar las mínimas condiciones para que la vida humana sea viable. En lo que corresponde al tipo de necesidades de mantenimiento, serán aquellas que pretenden que no disminuyan las condiciones que permitan seguir disfrutando de la libertad como no interferencia. Finalmente, la satisfacción de las necesidades de mejora pretende la optimización del desarrollo, crecimiento tanto físico, económico y cultura de todas las personas. Aquí cabrían los llamados derechos económicos, sociales y culturales, el derecho a la asistencia letrada, de los niños y niñas, personas con discapacidad. En todo caso, los llamados grupos vulnerables de la sociedad; por último, está la libertad de participación que promueve la intervención de las personas en la formación de los criterios de decisión política, así como el contribuir en los desarrollos legislativos, fines y valores de la actividad del Estado. Los derechos que fundamenta éste tipo de libertad, son, efectivamente, los llamados derechos políticos, de

5 CONSTANT, B., Principios aplicables a todos los gobiernos, Ed. Katz, Madrid, 2010, pp. 397-412; Véase también: BARBERIS, M., Benjamin Constant. Rivoluzione, costituziones, progresso, Ed. Il Mulino, Bologna, 1998, pp. 301-324.

6 BOBBIO, N., Liberalismo y democracia, Ed. Fondo de Cultura Económica de México, México, 2008, pp. 7-10, 32-38. 
participación ciudadana como el sufragio universal, así como aquellos que prevén la asociación política?.

En definitiva, los tipos de dimensiones de libertad que hemos visto, pueden trasladarse perfectamente a nuestro tema estudio. Inclusive, es posible redirigirlo en los tres esquemas. Así, en la libertad como no interferencia, la libertad de expresión es precisamente un derecho que todas las personas pueden llevar a cabo sin la necesidad de la actuación del Estado, ya que es un derecho que se ejerce libremente. Sin embargo, en caso de que éste sea vulnerado, (tal como veremos a continuación) es la libertad como promoción quien ingresa en escena para su protección. Ahora bien, en el caso de la libertad como participación, la libertad de expresión entra en dicho esquema, pues el ejercicio de tal derecho promueve entre otras cosas, la libre manifestación de las ideas así como un debate permanente en la vida democrática de un país determinado; claro está, en caso de ostentar y hacer valer la etiqueta de democrático.

En efecto, lo importante es que, para que se pueda hablar de Estado Constitucional, se está pensado en una Constitución que en su contenido reconozca y garantice un conjunto más o menos amplio de derechos. Desde una tradición liberal, al menos debe contener a las que Bobbio denominaba como "las cuatro grandes libertades de los modernos (personal, pensamiento, reunión y de asociación)"8. Si, además de los derechos de corte liberal se reconocen derechos políticos, hablaremos de un Estado Democrático, y si contiene derechos de tipo social, será entonces un Estado Social. Por consiguiente, si el código constitucional prevé de los tres tipos de derechos, se denomina Estado Social y Democrático de Derecho, o en una formulación que podría ser más simple, "democracia constitucional" 9 .

Los requisitos, no son otra cosa que unos determinados contenidos que se encuentran previstos en la Constitución. Esto es, no cualquier tipo de contenido, sino uno que será esencial para que la Constitución pueda llevar a cabo la función que históricamente el constitucionalismo demanda, que es: limitar al poder a través de mecanismos e instituciones propias del Derecho ${ }^{10}$, como pueden ser los derechos, incluido efectivamente, el derecho a la libertad de expresión.

\footnotetext{
7 PECES-BARBA MARTÍNEZ, G., Curso de derechos fundamentales, cit., pp. 227-228.

8 BOBBIO, N., El futuro de la democracia, Ed. Fondo de Cultura Económica de México, México, 1986, p. 26.

9 SALAZAR UGARTE, P. "EI nuevo constitucionalismo latinoamericano. (o un ornitorrinco jurídico), en Id., Política y derecho. Derechos y garantías. Cinco ensayos latinoamericanos, Ed. Fontamara, México, 2013, p. 52.

10 Véase: POZZOLO, S., Neocostituzionalismo e positivismo giuridico, ed. Giappiachelli, Torino, 2001, pp. 26-27. Efectivamente, tal como señala Salazar: "La Constitución del constitucionalismo tiene una función precisa: limitar el poder político con la finalidad de proteger los derechos individuales". SALAZAR UGARTE, P., La democracia
} 
Lo anterior empata perfectamente con el pensamiento de Elías Díaz, y a su ya famosa y tan citada frase: "No todo Estado es Estado de Derecho". El autor, a grandes rasgos señala que para ser un auténtico Estado de Derecho, habrá que reunir una serie de lineamientos o características en el que el Estado, se encuentre sometido al Derecho. Por tanto, las exigencias más básicas e indispensables de un Estado de Derecho pueden concretarse en la siguientes: a) Imperio de la ley; b) División de poderes; c) Legalidad de la administración y; d) Derechos y libertades fundamentales ${ }^{11}$. De esta forma, calza fielmente a un concepto que podría denominarse como mínimo por parte del constitucionalismo y que puede verificarse en lo dictado en el artículo 16 de la Declaración de los Derechos del Hombre y del Ciudadano del 26 de agosto de 1789, que reza de la siguiente manera: "Una sociedad en la que no esté asegurada la garantía de los derechos ni reconocida la división de poderes, no tiene Constitución".

Ahora bien, continuando con la fórmula de Elías Díaz, se puede afirmar entonces que: "no todo Estado con Constitución es un Estado constitucional ${ }^{12 " ~ a s i ́ ~ c o m o, ~ n o ~ t o d o ~ E s t a d o ~ d e m o c r a ́ t i c o, ~ e s ~ u n ~ E s t a d o ~}$ con democracia. Es decir, al igual que el Estado de Derecho, existen lo que podría denominarse como prerrequisitos o precondiciones de la democracia que deben ser garantizados. Aquí es, precisamente, donde cobra especial sentido la libertad de expresión, pues como afirma Tocqueville: "La prensa es el instrumento democrático por excelencia de la libertad"13.

Es innegable la importancia que tienen los derechos como límites al poder para la vida democrática de un Estado. De ahí, que la libertad de expresión juega un papel trascendental. Lo anterior, no ha sido desapercibido por lo estudiosos del derecho, y sobre todo, de aquellos que vislumbran los derechos como auténticos protagonistas del juego democrático. Por ejemplo, citando nuevamente a Elías Díaz, ha dejado ver de forma muy clara, la estrecha relación entre la libertad de expresión y democracia. Así, en palabras del profesor Díaz: "sin libertad $y$, por de pronto, sin libertad de opinión, no hay democracia, ni hay legitimidad democrática ni soberanía popular"14. Incluso, hay quien considera el derecho a la libertad de expresión como un "ideal

constitucional. Una radiografía teórica, Ed. Fondo de Cultura Económica de México, México, 2013, p. 72.

11 DÍAZ, E., Estado de derecho y sociedad democrática, Ed. Taurus, Madrid, 2010, p. 46.

12 ANSUÁTEGUI ROIG, F. J., Razón y voluntad en el Estado de Derecho. Un enfoque filosófico-jurídico, Ed. Dykinson, Madrid, 2013, p. 231.

13 TOCQUEVILLE, A., La democracia en América, Ed. Alianza, Madrid, 1980, p. 272.

${ }^{14}$ DÍAZ, E., De la maldad estatal y la soberanía popular, Ed. Debate, Madrid, 1984, p. 66. 
democrático"15. En este entendido, en una democracia, es esencial no solamente que los derechos como la libertad de expresión se encuentren estipulados. Lo que se necesita en todo caso, es que los derechos sean verdaderamente efectivos y que estos se encuentren cercanos a la población. De lo contrario, un sistema no puede llamarse democrático. Por consiguiente, frente a la falta de efectividad de los derechos y en nuestro caso, de la nula garantía de la libertad de expresión, cabría la alusión de Robert Dahl, ya que no pasan a ser solamente "adorno de la democracia, una mera fachada para un gobierno no democrático"16.

Por citar otro ejemplo con respecto a la importancia que merece la libertad de expresión en el juego democrático, es por demás interesante la postura de Santiago Nino. Es bien sabido que para el autor argentino, la democracia tiene un valor epistémico, en el que existen dos tipos de derechos que denomina como a priori y a posteriori. Nino, no duda en situar la libertad de expresión en los llamados derechos a priori, aún con la dificultad que representa categorizar los derechos. Así, justificando dicha posición, en palabras del propio autor: "El derecho a la libertad de expresión, que es por supuesto un derecho a priori, no requiere de ser libre de censura sino también de tener acceso positivo a los medios para comunicarse con otros"17.

En definitiva, los derechos son parte esencial y fundamental del Estado Constitucional y Democrático de Derecho. La importancia de ello, puede ser verificable en las Constituciones de cada Estado, esto es, si efectivamente se contempla tanto su reconocimiento, pero sobre todo, su efectividad, será en la medida en que los Estados se tomen en serio los derechos ${ }^{18}$. Por lo anterior, el panorama mexicano, (como veremos más adelante) no deja de ser paradigmático y problemático a la vez, pues nos encontramos con una dura realidad cuando hablamos de derechos. En el caso que nos ocupa, el derecho a la libertad de expresión ha sido vulnerado en repetidas ocasiones, silenciando de por vida tanto a periodistas como a defensores y defensoras de derechos humanos, lo que demuestra que el país Mexicano, es más bien un Estado en donde se hace evidente su falta de garantía.

15 SUNSTEIN, C., República.com. Internet, democracia y libertad, Ed. Paidós Estado y Sociedad, Barcelona, 2003, p. 153.

16 DAHL, R., La democracia, Ed. Ariel, Madrid, 2012, p. 59.

17 NINO, C.S., La Constitución de la democracia deliberativa, Ed. Gedisa, Barcelona, 2003, p. 193.

${ }^{18}$ Así lo ha manifestado Bobbio al señalar que: "El reconocimiento y la protección de los derechos humanos están en la base de la Constituciones democráticas modernas". BOBBIO, N., El tiempo de los derechos, Ed. Sistema, Madrid, 1991, p.14. 


\section{3.- MARCO JURÍdICO DE LA LIBERTAD DE EXPRESIÓN EN MÉXICO}

El derecho a la libertad de expresión, se encuentra reconocido por la ley de más alta jerarquía en el Estado mexicano, esto es, la Constitución Política de los Estados Unidos Mexicanos (en adelante, CPEUM). Es de recordar, que dicho documento constitucional ha cumplido ya sus 101 años de existencia desde aquel 5 de febrero de 1917 fecha en que se publicó en el Diario Oficial de la Federación, entrando en vigor hasta el 1 de mayo del mismo año. De forma muy general, la Constitución mexicana aportó en gran medida los llamados derechos sociales al mundo del constitucionalismo, siendo un documento pionero en dicha materia. Inclusive, puede decirse que ahí da inicio el llamado constitucionalismo social ${ }^{19}$.

En lo que respecta a la libertad expresión, la CPEUM lo reconoce en sus primeros artículos. De forma directa es visible tanto en el artículo $6^{\circ}$ y $7^{\circ}$ de la Constitución mexicana. Así, el artículo $6^{\circ}$ señala:

"La manifestación de las ideas no será objeto de ninguna inquisición judicial o administrativa, sino en el caso de que ataque a la moral, la vida privada o los derechos de terceros, provoque algún delito, o perturbe el orden público; el derecho de réplica será ejercido en los términos dispuestos por la ley. El derecho a la información será garantizado por el Estado.

Toda persona tiene derecho al libre acceso a información plural y oportuna, así como a buscar, recibir y difundir información e ideas de toda índole por cualquier medio de expresión"20.

A pesar de que el artículo $6^{\circ}$ de la CPEUM hace más referencia al derecho a la información, es evidente que se contempla también el derecho a la manifestación de las ideas. Sin embargo, es el artículo $7^{\circ}$ donde claramente el constituyente mexicano, evidencia su intención de reconocer tan elemental derecho. Dicho precepto constitucional reza de la siguiente manera:

"Es inviolable la libertad de difundir opiniones, información e ideas, a través de cualquier medio. No se puede restringir este derecho por vías o medios indirectos, tales como el abuso de controles oficiales o particulares, de papel para periódicos, de frecuencias radioeléctricas o de enseres y aparatos usados en la difusión de información o por

${ }^{19}$ En torno al surgimiento y desarrollo del constitucionalismo social, véase: VANOSSI, J., El Estado de Derecho en el constitucionalismo social, $3^{\circ}$ edición, Ed. Eudeba, Universidad de Buenos Aires, Argentina, 2000, p. 550. Desde una visión crítica: GARGARELLA, R., La sala de máquinas de la Constitución. Dos siglos de constitucionalismo en América Latina (1810-2010), Ed. Katz, 2014. En especial los capítulos: siete, ocho y nueve.

20 Constitución Política de los Estados Unidos Mexicanos. Disponible en: http://www.diputados.gob.mx/LeyesBiblio/pdf/1_150917.pdf 
cualesquiera otros medios y tecnologías de la información y comunicación encaminados a impedir la transmisión y circulación de ideas y opiniones"21.

El texto constitucional es por demás claro. La libertad de expresión es un derecho que debe ser respetado y garantizado, así lo estipula la Constitución mexicana. De hecho, existe un esfuerzo legislativo relativamente reciente derivado precisamente del artículo constitucional antes aludido, creando una ley especial en la materia. Nos referimos a la "Ley para la Protección de Personas Defensoras de Derechos Humanos y Periodistas"22. Esta ley federal, ha sido publicada en el Diario Oficial de la Federación apenas el pasado 25 de junio de 2012, contando con 67 artículos en donde se prevén fuertes sanciones para quienes violenten tan vital derecho. Lo que queremos destacar de dicha ley, es la creación de un instrumento jurídico, denominado: Mecanismo de Protección para Personas Defensoras de Derechos Humanos y Periodistas (en adelante, Mecanismo), exhortando que el Estado deberá atender su responsabilidad de proteger, promover y garantizar los derechos fundamentales. De las funciones que destacan del Mecanismo, se podrían señalar las siguientes:

El máximo órgano del Mecanismo, es la Junta de Gobierno, quien tendrá la última palabra para llevar a cabo acciones como: Medidas de Prevención, Medidas Preventivas, Medidas de Protección y Medidas Urgentes de Protección. Para acceder a dichas medidas, según el artículo 24 de la Ley, pueden ser solicitadas: I. Persona Defensora de Derechos Humanos o Periodista; II. Cónyuge, concubina, concubino, ascendientes, descendientes, dependientes de las Personas Defensoras de Derechos Humanos o Periodista; III. Personas que participan en las mismas actividades desde el mismo grupo, organización, o movimiento social; Los bienes de la persona, el grupo, organización, o movimiento social, y; V. Las demás personas que se determina en la evaluación de riesgo.

Es interesante el cómo la Ley, busca a toda costa la protección en caso de la vulneración tanto a personas defensoras como a periodistas. No obstante, a pesar del esfuerzo legislativo, y hay que decirlo, de las buenas intenciones del Congreso de la Unión del Estado mexicano, la violación sistemática de la libertad de expresión año con año, se hace cada vez más evidente. En todo caso, no debe de agotarse únicamente en un esfuerzo legislativo, habrá que tomar otro tipo de medidas gubernamentales para garantizar la efectividad de los derechos.

Lo anterior, ha sido el blanco de duras críticas y reclamos desde las coordenadas del llamado Derecho Internacional de los Derechos

${ }^{21}$ Constitución Política de los Estados Unidos Mexicanos, cit.

22 Ley para la Protección de Personas Defensoras de Derechos Humanos y Periodistas. Disponible en: http://www.diputados.gob.mx/LeyesBiblio/pdf/LPPDDHP.pdf 
Humanos (en adelante, DIDH), tal como veremos más adelante. Pues bien, es bien sabido que el DIDH adquiere su mayor auge el 26 de junio de 1945, capitalizándose con la firma de la Carta de las Naciones Unidos, que entró en vigor el 24 de octubre del mismo año; lo anterior significó un paso importante en materia de derechos humanos, que posteriormente daría luz, el 10 de diciembre de 1948, la Declaración de los Derechos Humanos. Al respecto, el autor italiano Luigi Ferrajoli denomina al texto declarativo como un "embrión constitucional del mundo"23, pues gracias a su realización, el DIDH da inicio su apogeo internacional. No es posible detenernos en todos los tratados internacionales en donde se hace referencia el derecho a la libertad de expresión. Sin embargo, consideramos especialmente relevante, la posición de la Corte Interamericana de Derechos Humanos que, a través de su jurisprudencia, ha dejado muy claro que la responsabilidad del Estado no se agota exclusivamente en la creación de leyes, las cuales pueden figurar como letra muerta, sino que, se deben implementar acciones firmes para dar efectividad y resguardo a los derechos fundamentales. En efecto, la sentencia emitida por la Corte el 29 de julio de 1988, denominada "Caso Velásquez Rodríguez Vs. Honduras", enfatiza lo anterior, exactamente en el párrafo 167:

"La obligación de garantizar el libre y pleno ejercicio de los derechos humanos no se agota con la existencia de un orden normativo dirigido a hacer posible el cumplimiento de esta obligación, sino que comparta la necesidad de una conducta gubernamental que asegura la existencia, en la realidad, de una eficaz garantía del libre y pleno ejercicio de los derechos humanos" 24 .

Asimismo, en el mismo "Caso Velásquez" pero ahora en el párrafo 166, se exhorta que los Estados partes deben organizar todo el aparato gubernamental, así como todas las estructuras por las cuales se pueden manifestar el ejercicio del poder público para asegurar en todo momento el libre y pleno ejercicio de los derechos humanos. Por lo tanto, y, como consecuencia de dicha obligación, los Estados deberán entonces prevenir, investigar, sancionar y en su caso, reparar toda violación de los derechos humanos. Incluso, el párrafo anterior es citado como precedente de la Corte en diversos fallos. Tal es el ejemplo de la sentencia a México en el caso "Radilla Pacheco Vs. Estados Unidos Mexicanos" de fecha de 23 de noviembre de 2009, en su párrafo $142^{25}$.

23 FERRAJOLI, L., Democracia y garantismo, Ed. Trotta, Madrid, 2010, p. 26.

24 Caso: Velásquez Rodríguez Vs. Honduras. Sentencia de 29 de julio de 1988. (Fondo). Corte Interamericana de Derechos Humanos. Disponible en: http://www.corteidh.or.cr/docs/casos/articulos/seriec_04_esp.pdf

25 Caso: Radilla Pacheco Vs. Estados Unidos Mexicanos. Sentencia de 23 de noviembre de 2009. (Excepciones preliminares, Fondo, Reparaciones y Costas). Corte Interamericana de Derechos Humanos. Disponible en:

http://www.corteidh.or.cr/docs/casos/articulos/seriec_209_esp.pdf 
En suma, no basta entonces con la creación de leyes para salvaguardar los derechos, sino de un compromiso serio y responsable por parte de todo el aparato gubernamental para hacerlos efectivos. Por tanto, en el caso de la libertad de expresión, no deja de ser pues un derecho de primera necesidad para la vida democrática de un Estado, tal como hemos visto más arriba. De hecho, desde las coordenadas del derecho internacional, se calcado el nexo inexorable entre la libertad de expresión y la democracia; así lo ha enfatizado la Organización de los Estados Americanos a través de un documento que se denomina "Carta Democrática Interamericana", aprobado en $2001^{26}$. Al respecto, tanto el $3^{\circ}$ y $4^{\circ}$ artículo del instrumento, se alude que la libertad de expresión y de prensa son elementos esenciales para el ejercicio de la democracia. Por consiguiente, habrá que garantizarlos en todo momento, ya que en caso de ser vulnerados, se estará violentando a la democracia misma. Tal como ocurre en el caso mexicano, como afirma Andrés Bertoni: "Cuando se asesina o amenaza a un periodista, no sólo su libertad de expresión y de la sociedad se pone en jaque: se amenaza a la democracia"27.

Por su parte, la importancia que merece la libertad de expresión en un Estado democrático, no ha sido ajena para el máximo intérprete constitucional en México. Nos referimos a la Suprema Corte de Justicia de la Nación (en adelante, SCJN).

Así por ejemplo, el pasado 20 de junio de 2013 el Pleno de la SCJN resolvió un asunto de acción de inconstitucionalidad 29/2011 que fue promovido por la CNDH contra un artículo del Código Penal de la entidad federativa de Veracruz, donde se sostiene que la libertad de expresión y de información son "centrales en un Estado constitucional democrático de derecho" y constituyen "pilares fundamentales". Se destaca que ambos derechos tienen una doble dimensión, y afirmó que: "gozan de una vertiente pública, colectiva o institucional que los convierte en piezas básicas para el adecuado funcionamiento de una democracia representativa". De esta forma, se enfatiza también que la libertad de expresión constituye un derecho que sirve de garantía para la realización de otros derechos y libertades. En este entendido, la SCJN expresó que "tener plena libertad para expresar, recolectar, difundir y publicar informaciones es imprescindible, no solamente como instancia esencial de auto-expresión y auto-corrección, sino también como premisa para poder ejercer plenamente otros derechos humanos -el de asociarse y reunirse pacíficamente con cualquier objeto lícito, el derecho

${ }^{26}$ Carta Democrática Interamericana. 11 de septiembre de 2001. Organización de los Estados Americanos. Disponible en:

http://www.oas.org/charter/docs_es/resolucion1_3s.htm

27 ANDRÉS BERTONI, E., Libertad de expresión en el Estado de Derecho, Ed. Editores del Puerto, Argentina, 2007, p. 192. 
Villanueva Sossa y Chávez Cervantes - La libertad de expresión y la defensa de los derechos humanos...

de petición o el derecho a votar y ser votado - y como elemento funcional que determina la calidad de la vida democrática de un país" 28 . La importancia que la propia SCJN de México ha dado en torno al derecho a la libertad de expresión, es de suma importancia, pues vincula su necesaria garantía con el Estado democrático. Incluso, con el objeto de proteger una esfera de deliberación pública. Es decir, que la garantía efectiva de la libertad de expresión e información, son derechos que potencian la vida política y democrática de un país. Así lo ha interpretado la SCJN el 20 de mayo de 2015 al declarar inconstitucional un artículo del Código Penal de la entidad federativa de Chiapas en donde se sancionaba con pena de prisión a toda persona que obtenga y brinde información de carácter confidencial o sea reservada para los cuerpos de seguridad pública o fuerzas armadas mexicanas. Aquí, la SCJN sostuvo que: "Ios derechos a la libertad de expresión y acceso a la información no sólo protegen libertades necesarias para la autonomía personal de los individuos, sino también pretenden proteger y garantizar un espacio público de deliberación política" 29.

\title{
4.- LIBERTAD DE EXPRESIÓN EN MÉXICO: SITUACIÓN ACTUAL
}

\author{
En nuestro último apartado, daremos cuenta con total desagrado
}

28 Suprema Corte de Justicia de la Nación, México. Acción de inconstitucionalidad 29/2011. Disponible en:

http://www2.scjn.gob.mx/ConsultaTematica/PaginasPub/DetallePub.aspx?AsuntoID=1 32774

29 Primera Sala. Suprema Corte de Justicia de la Nación. Amparo en Revisión. 492/2014. Disponible en:

http://www2.scjn.gob.mx/ConsultaTematica/PaginasPub/DetallePub.aspx?AsuntoID=1 67949

En otro asunto, la propia Primera Sala ha establecido que: “La libertad de expresión en su vertiente social o política, constituye una pieza central para el adecuado funcionamiento de la democracia representativa. En este sentido, se ha enfatizado la importancia de la libre circulación de las ideas para la formación de la ciudadanía y de la democracia representativa, permitiendo un debate abierto sobre los asuntos públicos. La libertad de expresión se constituye así, en una institución ligada de manera inescindible al pluralismo político, valor esencial del Estado democrático. Esta dimensión de la libertad de expresión cumple numerosas funciones, entre otras, mantiene abiertos los canales para el disenso y el cambio político; se configura como un contrapeso al ejercicio del poder, ya que la opinión pública representa el escrutinio ciudadano a la labor pública; y contribuye a la formación de la opinión pública sobre asuntos políticos y a la consolidación de un electorado debidamente informado. Dicho ejercicio permite la existencia de un verdadero gobierno representativo, en el que los ciudadanos participan efectivamente en las decisiones de interés público". Tesis aislada CDXIX/2014 de esta Primera Sala de la Suprema Corte de Justicia de la Nación, visible en la página 234 del Libro 13 (diciembre de 2014) Tomo 1, de la Gaceta del Semanario Judicial de la Federación, de rubro: "LIBERTAD DE EXPRESIÓN. DIMENSIÓN POLÍTICA DE ESTE DERECHO FUNDAMENTAL." 
Villanueva Sossa y Chávez Cervantes - La libertad de expresión y la defensa de los derechos humanos...

lo ensangrentado que se encuentra el ejercicio de la libertad de expresión y prensa en México. Por desgracia, las cifras que a continuación detallaremos, son el fiel reflejo de una situación poco alentadora en términos de derechos. De entrada podemos aseverar, que el Estado y todo su aparato gubernamental, se ha visto sobrepasado en la misión de garantizar los derechos humanos en México. Al menos, desde la óptica del resguardo de la libertad de expresión, lo anterior es perfectamente verificable.

México, es uno de los tantos países que no se escapa de vivir crisis de seguridad, acarreando con ello, una afectación a los derechos humanos de forma generalizada. Los crímenes vividos en nuestro país, como asesinatos, desapariciones o torturas; apuntalan más a aquellas personas que se encargan de contar las historias de los conflictos, corrupción, trafico, involucramiento de autoridades públicas con el crimen organizado, guerra contra el narco, violencia policiaca, asuntos relacionados con las elecciones, criminalidad e inseguridad, es decir, hacia las personas defensoras de derechos humanos y periodistas, representando con ello la amenaza más inmediata y desafiante a la libertad de expresión, a la condición básica para el sano desarrollo de las sociedades democráticas.

A pesar de existir un Mecanismo Nacional para la Protección de los Defensores de Derechos Humanos y Periodistas ${ }^{30}$, (tal como hemos visto más arriba) las cifras que muestran diversos organismos en torno a los ataques que se han visto expuestos tanto periodistas como personas defensoras de derechos humanos, son alarmantes, representando únicamente una insignificante parte de la realidad.

Ahora bien, el documento que consideramos más revelador, tanto por su reciente emisión así como por la credibilidad del organismo que lo publica, es un informe emitido apenas el pasado 4 de diciembre de 2017. La elaboración del documento fue comandada por el Relator Especial de la ONU sobre la Libertad de Expresión, así como el Relator Especial sobre Libertad de Expresión de la Corte Interamericana de Derechos Humanos, después de una visita conjunta al Estado mexicano del 27 de noviembre al 4 de diciembre de 2017. En dicho informe, exactamente en el párrafo 12, se señala: "Los ataques endémicos en

30 Este mecanismo adoptado después de que el Gobierno creara la Ley para la Protección de Defensores de Derechos Humanos y Periodistas, el 25 de Junio de 2012. Proporcionando, desde su creación, la protección a 349 periodistas y de 130 que han buscado protección durante el 2017 el 98\% de los casos se han incorporado. Dicha Ley lo que permite es que el Estado atienda la responsabilidad de proteger, promover y garantizar los derechos humanos promoviendo medidas preventivas que garanticen la vida, integridad, libertad y seguridad de las personas que se encuentren en situación de riesgo como consecuencia de la defensa o promoción de los derechos humanos, y del ejercicio de la libertad de expresión y el periodismo. Véase:

http://www.diputados.gob.mx/LeyesBiblio/pdf/LPPDDHP.pdf 
contra de periodistas, así como de las personas de derechos humanos, sin duda representan la amenaza más inmediata y desafiante a la libertad de expresión en México hoy en día"31.

Además, el propio documento, manifiesta que no existe un sistema único para obtener y recolectar datos sobre ataques contra periodistas y defensores de derechos humanos. Por lo que, se ciñen de los datos que recolecta la Comisión Nacional de los Derechos Humanos de México, (en adelante, CNDH) o también conocidas como defensorías del pueblo, arrojando cifras que son un tanto catastróficas. Desde el 2010, 73 periodistas han sido asesinados; 12 han sufrido desaparición forzada, mientras que ha habido 44 intentos de asesinatos. A partir de 2006, se han contabilizado 52 ataques contra medios de comunicación. Es de advertir, que el informe ha visto plausible los esfuerzos legislativos así como la creación del Mecanismo ya antes señalado. Sin embargo, es por demás evidente que no ha sido suficiente. Por lo que se insta al Estado a proporcionar mayor financiamiento al Mecanismo, ya que los recursos que le son asignados para operar son bastantes precarios y más, frente a la realidad que demanda el Estado. La importancia de dicho Mecanismo es tal, que durante el año de 2017, 130 periodistas han buscado protección, de los cuales, el $98 \%$ de los casos se han incorporado a los medios de protección y atención que proporciona el Mecanismo. En todo caso, es evidente que se necesita dotar de más recursos al Mecanismo para incorporar el personal indispensable y dar atención a lo largo y ancho de la República mexicana, independientemente de los esfuerzos que lleven a cabo cada entidad federativa 32 .

Por su parte, La CNDH advierte que en 2011 aconteció un incremento en las agresiones cometidas a este grupo $y$, que dentro de este Organismo Nacional, existe un mecanismo denominado: Programa de Agravios a Periodistas y Defensores Civiles de Derechos Humanos. En dicho mecanismo, se integraron un total de 380 expedientes respecto a casos donde se encuentran involucradas personas defensoras de los derechos humanos. Los datos que se contabilizan comprenden desde el $1^{\circ}$ de enero de 2006 al 31 de diciembre de 2015. Por otro lado, solo el $50 \%$ de las 32 entidades federativas que conforman el Estado mexicano, presentaron informes sobre quejas realizadas en sus respectivas

31 Observaciones preliminares del Relator Especial de la ONU sobre la libertad de expresión y el Relator Especial sobre la libertad de expresión de la CIDH a México. 2017. Disponible en:

http://www.oas.org/es/cidh/expresion/docs/Observaciones_Preliminares_ESP.PDF

32 Observaciones preliminares del Relator Especial de la ONU sobre la libertad de expresión y el Relator Especial sobre la libertad de expresión de la CIDH a México, cit. 
Villanueva Sossa y Chávez Cervantes - La libertad de expresión y la defensa de los derechos humanos...

defensorías del pueblo, durante el periodo 2000 a $2015^{33}$. La siguiente tabla, muestra de forma más detallada el número de quejas, así como la entidad donde se llevaron a cabo.

\begin{tabular}{|l|l|}
\hline $\begin{array}{l}\text { Entidad } \\
\text { Cederativa }\end{array}$ & Información \\
\hline Campeche & 5 expedientes de queja (no se especifica grupo vulnerable) \\
\hline Chihuahua & $\begin{array}{l}\text { Desde } 2008 \text { sólo se tuvo conocimiento de } 10 \text { casos donde } \\
\text { defensores de derechos humanos fueron asesinados y } 4 \\
\text { amenazados. }\end{array}$ \\
\hline Coahuila & 20 casos (no se especifica grupo vulnerable). \\
\hline Colima & 10 quejas (no se especifica grupo vulnerable). \\
\hline $\begin{array}{l}\text { Ciudad de } \\
\text { México }\end{array}$ & $\begin{array}{l}18 \text { quejas relacionadas con el tema de defensores de derechos } \\
\text { humanos. }\end{array}$ \\
\hline Edo de México & $\begin{array}{l}\text { Del } 2009 \text { al } 5 \text { de abril del } 2015 \text { se registran } 38 \text { quejas (no se } \\
\text { especifica grupo vulnerable). }\end{array}$ \\
\hline Guerrero & $\begin{array}{l}\text { Del } 2008 \text { al } 2015 \text { se registran } 23 \text { quejas (no se especifica grupo } \\
\text { vulnerable). }\end{array}$ \\
\hline Nuevo León & $\begin{array}{l}\text { De } 2009 \text { al } 2015 \text { se registran } 5 \text { casos (no se especifica grupo } \\
\text { vulnerable). }\end{array}$ \\
\hline Oaxaca & $\begin{array}{l}\text { Del } 2000 \text { al } 2005 \text { se registran } 25 \text { quejas en agravio a personas } \\
\text { defensoras de derechos humanos. }\end{array}$ \\
\hline Puebla & $\begin{array}{l}\text { Del } 2000 \text { al } 2015, \text { se registran } 38 \text { quejas reportadas en agravio } \\
\text { a personas defensoras de derechos humanos. }\end{array}$ \\
\hline San Luis Potosí & $\begin{array}{l}\text { Del } 2007 \text { al } 2014 \text { se presentan } 2 \text { quejas tramitadas (no se } \\
\text { especificar grupo vulnerable). }\end{array}$ \\
\hline Sinaloa & $\begin{array}{l}\text { Del } 2008 \text { al } 2015 \text { se presentan } 6 \text { quejas registradas en agravio a } \\
\text { personas defensoras de derechos humanos. }\end{array}$ \\
\hline Tabasco & $\begin{array}{l}\text { De } 2000 \text { a } 2015 \text { se presentan } 2 \text { quejas (sin especificar grupo } \\
\text { vulnerable). }\end{array}$ \\
\hline Tamaulipas & $\begin{array}{l}\text { Se presentan } 2 \text { quejas (sin especificar grupo vulnerable). } \\
\text { Se presentan } 2 \text { quejas (sin especificar grupo vulnerable). } \\
\text { Tlaxcala } \\
\text { vulnerable. }\end{array}$ \\
\hline Veracruz & \begin{tabular}{l} 
Del 2013 al 2015 se presentan 3 casos, sin especificar grupo \\
\hline
\end{tabular} \\
\hline
\end{tabular}

Respecto a los homicidios de personas defensoras de derechos humanos, se puede apreciar que el año 2011 hubo un incremento en el número de civiles asesinados; y que los Estados de Chihuahua, Guerrero y Oaxaca, son los que muestran una mayor incidencia en agravio a este grupo de personas ${ }^{34}$.

33 Datos recabados de la Recomendación General No. 25 emitida por la Comisión Nacional de Derechos Humanos, sobre agravios a personas defensoras de Derechos Humanos (publicado 8 de febrero de 2016). Véase en:

http://informe.cndh.org.mx/uploads/menu/15002/RecGral_025.pdf

34 Datos recabados de la Recomendación General No. 25 emitida por la Comisión Nacional de Derechos Humanos, sobre agravios a personas defensoras de Derechos Humanos (publicado 8 de febrero de 2016). Véase en:

http://informe.cndh.org.mx/uploads/menu/15002/RecGral_025.pdf 
Villanueva Sossa y Chávez Cervantes - La libertad de expresión y la defensa de los derechos humanos...

\begin{tabular}{|l|c|l|}
\hline Año & Casos & Entidades federativas \\
\hline 2010 & 6 & Chihuahua (4), Oaxaca (2) \\
\hline 2011 & 8 & Chihuahua (4), Guerrero (3), Sonora (1) \\
\hline 2012 & 3 & Oaxaca (1), Puebla (1), Guerrero (1) \\
\hline 2013 & 4 & Oaxaca (1), Guerrero (2), Veracruz (1) \\
\hline 2014 & 1 & Sinaloa \\
\hline 2015 & 3 & Veracruz (1), Chihuahua (1), Ciudad de México (1) \\
\hline
\end{tabular}

En cuanto a las agresiones cometidas a periodistas podemos tener un panorama aún menos alentador. En 25 de las 32 entidades federativas concurrieron 20 casos de desaparecidos y 48 atentados en contra de medios de comunicación (periodo 2005 a 2015). Del 2000 al 2015, se integraron en el Programa de Agravios a Periodistas y Defensores Civiles de Derechos Humanos, un total de 1049 expedientes de quejas, las cuales estaban relacionadas con presuntas violaciones a derechos humanos cometidas en su agravio.

Como se puede observar la diferencia de las agresiones a periodistas y a personas defensoras de derechos humanos es significativa; el dato más relevante es sin duda el de homicidios, ya que para el grupo de los defensores suman 25 decesos, a diferencia de los 107 a periodistas, durante el periodo 2010-2015. Entre las entidades federativas más peligrosas con respecto a este rubro, se encuentran: Oaxaca $(11 \%)$, Chihuahua $(11 \%)$, Guerrero $(11 \%)$, Tamaulipas $(11.9 \%)$ y Veracruz $(14.6 \%)$, donde 6 de cada 10 homicidios sucedieron en estas 5 entidades ${ }^{35}$.

Las cifras expuestas, muestran un panorama aterrador y lamentablemente este no se aproxima ni un poco a la realidad, pues se tiene claro que la mayoría de las agresiones efectuadas, no se denuncian, ya sea por falta de confianza en la autoridad o por temor a sufrir alguna represalia. Empero, tanto los llamamientos del Relator de la ONU como del Relator de la CIDH, sumado con los datos que nos arroja la $\mathrm{CNDH}$, nos proporcionan una especie de radiografía de lo que sucede en México, destacando entonces que, el ejercicio de tan vital derecho carece de garantías, potenciando de manera significativa un riesgo para quien ejerce la libertad de expresión; al grado incluso de firmar su propio condena de muerte.

35 Recomendación General No. 25 emitida por la Comisión Nacional de Derechos Humanos, sobre agravios a personas defensoras de Derechos Humanos (publicado 8 de febrero de 2016). Véase en:

http://informe.cndh.org.mx/uploads/menu/15002/RecGral_025.pdf

Recomendación General No. 24. Emitida por la Comisión Nacional de los Derechos Humanos, sobre el ejercicio de la libertad de expresión en México, (publicado 8 de febrero de 2016). Véase en:

http://informe.cndh.org.mx/uploads/menu/15004/RecGral_024.pdf 
Por último, mencionar que únicamente se presentan los datos que consideramos más significativos con respecto a las agresiones en contra de periodistas y personas defensoras de derechos humanos. No obstante, el periodo que aquí se expone se da entre 2009 a 2015. A pesar de que en México durante este periodo ha logrado un cambio legislativo por demás significativo, en el que se crea el Mecanismo, es por demás evidente que no ha sido suficiente, pues gran parte de las agresiones se han cometido posterior a su existencia.

\section{5.- REFLEXIONES FINALES}

Tiene mucha razón Bobbio al señalar que: "Pero una cosa es proclamar este derecho, y otra cosa satisfacerlo efectivamente" ${ }^{\prime 36}$. Durante el desarrollo e investigación del presente artículo, nos hemos encontrado con una realidad que demanda una gran responsabilidad por parte del Estado mexicano para hacer efectivos los derechos humanos. Hemos insistido bastante en la conexión que existe entre la libertad de expresión y el Estado Constitucional, en donde el primero, juega un papel fundamental en el esquema democrático de una comunidad política y, en caso de que éste no se encuentre garantizado, se pone en jaque a la democracia misma. Por consiguiente, pensamos que la democracia en México depende prácticamente de un hilo, pues uno de sus pilares como la libertad de expresión representa todo un riesgo su ejercicio, ya que como hemos visto en las cifras arriba expuestas, las personas que se dedican a informar se ven altamente expuestas a amenazas e incluso al grado de perder la vida. Lo que es totalmente alarmante, y más, en un Estado que suele denominarse como democrático, ya que la realidad que se vive en México es totalmente antagónica con el propio ideal de la democracia. De esta forma, la vulneración a la libertad de expresión trasgrede tanto su vertiente activa y pasiva, esto es, el hecho de no existan garantías para ejercer la libertad de expresión, el derecho a la información se ve también trasgredido. Dicho de otra forma, al garantizar el ejercicio a la libertad de expresión, se estará procurando por tanto el derecho a la información. Lo anterior es fundamental, ya que se atenta a esta doble dimensión, pues evidentemente al violentar a los encargados de difundir información así como los medios de comunicación, se nulifica el derecho de toda una comunidad a ser informada. Por tanto, instamos que las demandas de la Corte Interamericana a los Estados son especialmente relevantes. En efecto, se exhorta la necesidad legislativa, demandando además el proporcionar los medios económicos que solventen las necesidades materiales para el buen funcionamiento de los respectivos

${ }^{36}$ BOBBIO, N., El tiempo de los derechos, cit., p. 22. 
mecanismos que procuran y defienden los derechos. Como es el caso del Mecanismo que protege a periodistas y defensores de los derechos en México.

Es por ello, que en la introducción del presente artículo se hace alusión en lo determinante que representa la anualidad que transcurrimos, ya que el Estado Mexicano está inmerso en año electoral y precisamente el discurso de los derechos sale a relucir en boca de todas y todos los candidatos; en el que se escucha replicar una y otra vez, un fuerte compromiso y responsabilidad por garantizar los tan anhelados derechos de la población en general. Esperemos entonces, que la bandera de los derechos no sea únicamente una bandera electoral. Que una vez obtenidos los sufragios necesarios y ostenten tan honroso cargo de elección popular, se olvide por completo la bandera que tanto alzaron y presumieron defender. En todo caso, habrá que recordar a quien resulte vencedor o vencedora, que la bandera de los derechos debe defenderse en campaña o no campaña electoral, se gane o se pierda y, en caso de que los resultados les favorezcan, no olvidarse de tan importante compromiso, ya que estarán en el mejor de los escenarios para hacer efectivos los derechos. Pues, tomarse en serio el derecho a la libertad de expresión, es tomarse en serio la democracia y por tanto la propia Constitución. 